\section{TWO CASES OF "ELECTRIC-LIGHT BLINDNESS."}

BY ROBERT HILL, M.R.C.S. ENG., L.R.C.P. LoND., SURGEON, ROYAL NAVY (H.M.S. "VICTORY").

I VENTURe to forward for publication in THE LANCHT the following cases that have come under my notice lately, hoping that they may be of interest to its readers, and more especially to those engaged in ophthalmic work.

CASE 1.-About 1 A.M. on June 1st, 1897, I was called hurriedly to see a man who was said to be suffering great pain in his eyes. The man, a stoker, twenty years of age, I found walking round the sick bay of this ship in an agony of pain, with his hands up to his eyes from which the tears were literally pouring. The lids were kept firmly closed, and all my efforts to see the eyes proved futile until $I$ had dropped in cocaine, which acted like a charm. Five minutes later he could distinguish the number of persons in the room, but not the number of fingers held up. The pupils were moderately dilated (probably due to the cocaine); the palpebral conjunctiva was deeply congested, with but slight reddening of the balbar conjunctiva; the cornea was clear. I imagined some irritant had been applied, but he denied this, nor could I find any trace of any substance such as pepper likely to cause the condition. Cold applications were used and the patient soon fell asleep. At 8 A.M. his vision was normal, but the conjunctiva was injected, and he complained of a sticky sensation in his eyes. He then gave me the following history. When at work in H.M.S. Mars on the afternoon of May 31 st he had stopped for about three minutes to look at the electric drill which was being used to bore holes in a steel plate, standing at a distance of from ten to twelve yards; on resuming his own work everything appeared to him of a deep gold colour, but he had no pain or lacrymation. He turned into his hammock at 9 P.M., and woke up in great pain at 1230

CASE 2.-At 9 A.M. on June 1st a stoker, aged twentyeight years, who had been sleeping on shore, came to the sick bay complaining of his eyes. He stated that he had been working in H.M.S. Mars on the previous afternoon, and, like the patient in Case 1, had stopped to see the electric drill working, and had noticed during the remainder of the day that everything appeared of a deep gold colour. About 4 A.M. he had jumped out of bed in great pain, and this had lasted about an hour and a half. The condition of the eyes was very similar to that described in Case 1 -injection of the conjunctiva being the only abnormal condition. Vision was normal.

Ever since the electric light has been in use workers at this trade have been subject to attacks of blindness, and cases have been recorded in which erosion of the cornea has followed the inflammation induced. Dark glasses are now always used by men so employed. The electric drill acts by fusing a hole through the steel, and probably the intensity of the light is greatly increased by the rays of light thrown off by the molten metal. The fact that the work is carried on chiefly in the daylight hides to a casual passer-by the extreme brilliancy of the light, and it is not until the patient experiences abnormal colour sensations that he is aware of anything extraordinary. When first this drill was used in Chatham Dockyard Surgeon P. N. Randall had a few similar cases among the dockyard hands, but as they slept on shore he had no opportunity of observing the acuteness of the pain.

The pathology of this condition has been stated to be similar to that of snow-blindness or desert blindness, and to depend on irritation of the branches of the ophthalmic division of the fifth nerve. In the cases above recorded the irritation would appear to have gone on to absolute paralysis and the pain to have been due to the acute congestion attending the nerves in their action of regaining their normal function. A somewhat analogous train of circumstances is found in the paralysis of the sensory nerves of other parts of the body when exposed to extreme cold, such as the ether spray or frost-bite, and the pain in these cases is often very great when the eongestion attending the "coming to" of the part takes place. The short period during which the severe pain lasted is also in favour of this analogy. The close sympathy that exists between the second nerve and the branches of the ophthalmic division of the fifth nerve is shown in many common and well-known reflexes, such as lacrymation and sneezing on sudden exposure of the eye to a bright light, or, conversely, the dread of light that is caused by any injury to the cornea. In the class of cases described we have a marked instance of the first class of reflex. A temporary paralysis of some of the optic nerve terminals is induced by the exposure to the intense light and heat of the electric drill as shown by the subjective colour sensations experienced. The corneal terminals reflexly share in the paralysis ; lacrymation and photophobia are absent because the nerve terminals are paralysed and not merely irritated at the time. After the lapse of a few hours a reaction with temporary congestion is set up as manifested by the acute pain and lacrymation, and probably some mistiness of vision. The longer the exposure to the bright light the profounder the paralysis and the more intense and lasting the reactionary symptoms. These cases are, in fact, analogous to snow-blindness, and, as in them, the pernicious effects of the electric light are probably due to the ultra violet rays of the spectrum.

Portsmouth.

\section{THE TREATMENT OF LACRYMAL OBSTRUCTION BY STYLES.}

BY R. SHALDERS MILLER, F.R.C.S. ENG.

THIs little section of surgical therapeusis has probably been less successful than the operative treatment of other disorders of the eye and its subsidiary apparatus.

Since 1877, when I first became a clinical assistant at the Royal London Ophthalmic Hospital, Moorfields, it has been my habit to treat all organic strictures of the lacrymal duct-that is, all parts of the outfall from the lower punctum lacrymale to the exit in the inferior turbinate sinus of the

FIG. 1.


shows the wire (magnified for clearness) with an oblique notch filed in the end to fit into the angle between the arm and the 8 in. notch place where the stem is cut off.

nose-by styles, in most cases permanently retained. Except for temporary wear they should be made of pure platinum wire, about 25 gauge, and I always make them myself for each individual case. The shape, direction, and length of the nasal duct being variable this special adaptation is the key to success in the use of styles, which consist of a vertical stem with a short arm bent at or about a right angle to the stem and usually this arm is made double by recurving the wire back to the stem, so that the arm consists of two thicknesses of wire, parallel and quite close together, the recurved part being vertically beneath the other, or upper, part. In this way the slit in the edge of the lid is just filled up, bat no 